\title{
Best Approach for Low-Risk Superficial Bladder Cancer
}

\author{
Eduardo Solsona \\ Service of Urology, Instituto Valenciano de Oncologia, Valencia, Spain \\ E-mail: solsona@pulso.com
}

Received April 10, 2006; Revised October 2, 2006; Accepted October 3, 2006; Published October 23, 2006

\begin{abstract}
In order to create better criteria for different grades of superficial bladder tumor, the WHO and ISUOP develop a new classification in 1998, which was modified in 2004. Although the new classification might be more reproducible, it has not yet been widely accepted. The low risk groups include patients with single $\mathrm{Ta}, \mathrm{G} 1, \leq 3 \mathrm{~cm}$ diameter tumors. This group has high recurrence and low progression rates. The standard treatment is the complete resection and postoperative single immediate instillation of whatever chemotherapy agent should be considered.
\end{abstract}

KEYWORDS: bladder tumor, superficial, non-muscle invasive, low-risk, chemotherapy

\section{INTRODUCTION}

The classification of superficial bladder tumor or better-known nonmuscle-invasive bladder tumors is based on two pillars: (1) the clinical stage following the TNM classification differentiating between Ta, which includes tumors not invading the submucosa, and T1, which invades the submucosa, but not the muscularis propria; and (2) the histological grade that refers to the 1973 WHO grading system based on the microscopic appearance of cancer cells. However, the major limitation of this classification is the vague definition and the lack of specific histological criteria without a reliable inter- and intraobserved correlation[1]. Attempting to create better criteria for different grades in 1998, the WHO and ISUOP developed a new classification, which was modified in 2004[2,3] and included papilloma. G1 tumors were reclassified as papillary urothelial neoplasms of low malignant potential (PUNLMPs) or true low-grade tumors, G2 tumors were also reclassified as low grade and high grade according to specific cytological and histological architectural criteria, and G3 tumors remained as high-grade carcinomas. Until the new classification system is validated, we can use both former and new classifications, and the risk groups are prevailing.

Although the new classification might be more reproducible, it has not yet been widely accepted. Currently, the risk groups of nonmuscle-invasive bladder tumors are under revision, as the classic risk groups are based on the combination of recurrence and progression risks, and many times, both are not parallel in individual and collective bases[4]. Assuming these limitations and following the European Guidelines definition, the low-risk group includes patients with single, Ta, G1, $\leq 3 \mathrm{~cm}$ diameter tumors[5]. This group is characterized by a mean recurrence and progression percentage of 36.5\% (range 29-48\%) and of 3.3\% (range 0-7\%) at a 5-year follow-up, respectively[6,7]. With these biological characteristics, patients included in the low-risk group have an excellent biological behavior with no life-threatening, but 
with moderate, recurrence rate, which compromises their quality of life, requiring many transurethral resections and cystoscopies during follow-up.

As a whole, in patients with TaG1 tumors, the recurrence rate depends on the follow-up length; 40 and $71 \%$ at 3 and 5 years of follow-up[8,9]. Also, this recurrence rate is related to multiple tumors, recurrence at 3 months, and previous recurrence rate[10]. All these variables define a subgroup of patients with high recurrence rate, regardless of the therapy applied.

\section{INCIDENCE}

Nonmuscle-invasive bladder cancer comprises the most prevalent group of bladder tumors, around 75\%, and the Ta category represents almost $50 \%$ of the newly diagnosed nonmuscle-invasive tumors and $70 \%$ of these were low grade[8]. In the Millan et al. series[7], the low-risk group represented $11.5 \%$ of the whole series of patients with nonrecurrent, nonmuscle-invasive bladder tumors. Although there are demographic differences between European countries and other worldwide countries, the low-risk group of nonmuscle-invasive bladder tumors is a very frequent entity in the uro-oncology field.

\section{DIAGNOSIS}

Cystoscopy and cytology are the mainstream methods for the diagnosis of bladder tumors, but the question is if there are reliable cystoscopic findings to identify low-risk tumors. In two studies, Herr[11] correlated the cystoscopic appearance of bladder tumors and their pathological examination. Patients with tumors $<0.5$ $\mathrm{cm}$, with discrete papillary fronds and a visible fibrovascular core were considered as TaG1 tumors. In a retrospective study, 78 (93\%) of those considered cystoscopically TaG1 were histologically proven; when urinary cytology was negative, the correlation was $99 \%$. In this series, only $7 \%$ of low-grade tumors diagnosed cystoscopically were high grade and $2 \%$ of invasive tumors in pathological examination. These figures were also corroborated in a prospective study with 94 and 99\% correlation between cystoscopy and histology in patients with TaG1 appearance and with negative urinary cytology, respectively[12].

In a randomized trial defining low-risk, nonmuscle-invasive bladder cancer, when papillary (thin fronds), $<3 \mathrm{~cm}$, single, primary, or recurrent with disease-free for more than 1 year, it was found that during the first cystocopic evaluation, $3 \%$ were invasive bladder tumors, $1.5 \%$ were G3, and $0.7 \%$ were bladder Tis[13]. With similar criteria, Oosterlink et al. observed that 5.6\% of patients had muscle-invasive tumors[14].

Cina et al.[15], in nonselected patients, did not find a good correlation between cystoscopic appearance and histology; $54 \%$ of papillary tumors of high-grade appearance at biopsy were of low-grade appearance on cystocopy, $19 \%$ of those considered to be low grade on cystoscopy were high grade at biopsy, and 33\% of high-grade appearance on cystocopy were low grade by pathological examination.

The discrepancy between this and previous series was probably due to the strict selection criteria used in theformer series and the unselected character of patients included in the Cina et al. series[15]. According to these data, urinary cytology takes an important part in the bladder tumor assessment. A positive cytology excludes tumors at low risk and a negative cytology contributed to identifying tumors at low risk.

The need for intravenous urography at the initial diagnosis of bladder tumor is rather questionable, as the incidence of upper urinary tract tumors is extremely low, ranging from $0.3-2.3 \%[10]$. A relation has been observed between grade and stage of bladder tumors and the incidence of upper urinary tumors: $0 \%$ for $\mathrm{G} 1,1.1 \%$ for $\mathrm{G} 2$, and $1.3 \%$ for G3; and $0 \%$ for Ta and $7 \%$ for T1[16]. In addition, the prognosis of patients with TaG1-2 does not seem to be threatened by the diagnosis delay of upper urinary tract tumors until they are symptomatic[17]. As a consequence, we can speculate that the incidence of upper urinary tract tumors in patients with low risk of nonmuscle-invasive bladder cancer is extremely low and a routine intravenous urography is not justified. 


\section{TREATMENT}

The standard treatment for patients with nonmuscle-invasive bladder cancer is the complete transurethral resection (TUR) of all bladder tumors. The TUR technique should be performed in fractionated fashion, removing the exophytic part first, the endophytic part (including muscularis propria) second, and the surrounding tissue of the tumor pedicle third. The inclusion of muscle in the second specimen is essential to carry out a correct staging. However, small tumors with clinical and cytological characteristics of lowrisk tumor can be resected in only one chip, but the muscle inclusion in the chip is also important to establish the right stage.

Although residual tumors are related to the quality of the TUR[18], this is a very frequent event and also related to number, grade, and stage[19]. In two randomized trials with clinical criteria for low risk, a low recurrence rate (3-7\%) was observed at the first cystoscopy in observation arms[13,14]. This suggests that the residual tumor in this group is not a relevant event and the indication of a second TUR 4-6 weeks after the initial TUR seems to be unrealistic.

Classically, the most common approaches for patients at low risk were observation alone or standard intravesical chemotherapy. With observation only, the recurrence rate is around $40 \%$, meaning that a great number of TURs and endoscopic assessments should be performed in patients with no lifethreatening disease according to the extremely low progression rate. Standard intravesical chemotherapy obviously reduces the recurrence rate in these patients, but it could be an overtreatment with a significant rate of side effects and high economic cost.

Between both approaches, an immediate single instillation of a chemotherapy agent was prompted according to the results of four phase II trials, which suggests that an immediate single instillation of intravesical chemotherapy after TUR reduced the recurrence rate[19,20,21,22,23]. These preliminary results encouraged an undertaking of randomized trials in order to demonstrate the effectiveness of this approach.

The Medical Research Council[24] carried out a phase III trial that compared a single instillation of thio-tepa, a 3-month instillation for 1 year, and TUR alone. No significant difference of recurrence rate was reported between the three arms. Afterwards, another large randomized trial from EORTC, with a mean follow-up of 2 years, a significant reduction of recurrence rate, and the interval to the first recurrence, was found in patients treated with a single immediate instillation of epirubicin compared to TUR plus water[14]. Five other randomized trials showed a significant reduction of recurrence rate in patients receiving a single immediate instillation of chemotherapy agents compared to those included in the controlled arm (Table 1). Evaluating the efficacy of this approach, a 12\% recurrence rate reduction was observed in patients treated with active agents compared to the control group.

TABLE 1

Randomized Trials Comparing Immediate Intravesical Chemotherapy and Control Arms

\begin{tabular}{lccccc}
\hline & & & & \multicolumn{2}{c}{ Recurrence Rate } \\
\cline { 5 - 6 } Author (Year) & Patients & Timing & Agent & $\begin{array}{c}\text { RTU } \\
\text { (Agent) }\end{array}$ & $\begin{array}{c}\text { RTU } \\
\text { (Control) }\end{array}$ \\
\hline Oosterlink et al. (93) & 399 & $6 \mathrm{~h}$ & Epirubicin & $28.3 \%$ & $37.5 \%$ \\
MRC (95) & 379 & Unknown & Thiotepa & $37.3 \%$ & $41.9 \%$ \\
Tolley et al. (96) & 306 & $24 \mathrm{~h}$ & Mitpmycin C & $48.3 \%$ & $59.8 \%$ \\
Ali-El-Dein et al. (97) & 109 & Immediate & Epirubicin & $23.6 \%$ & $51.8 \%$ \\
Solsona et al. (99) & 131 & $6 \mathrm{~h}$ & Mitomycin C & $40.3 \%$ & $54.6 \%$ \\
Rajala et al.(02) & 134 & Immediate & Epirubicin & $45.5 \%$ & $72.7 \%$ \\
Okamura et al. (02) & 160 & $6 \mathrm{~h}$ & Pirarubicin & $25.9 \%$ & $43 \%$ \\
Total & 1618 & & & $36.7 \%$ & $48.4 \%$ \\
\hline
\end{tabular}


In trials using a single immediate instillation, different chemotherapy agents were used with similar efficacy except for thio-tepa. Nevertheless, in other two trials[20,29] using higher doses of thio-tepa (60 and $90 \mathrm{mg}$.) than the MRC trial (30 mg), the recurrence rate was reduced in patients receiving thio-tepa. As a whole, $50.5 \%$ of recurrence was observed in the control arm and $35.6 \%$ in patients treated with a single instillation of a chemotherapy agent with epirubicin, mitomicin C (MMC), or pirarubicin.

In a recent meta-analysis, Sylvester et al.[30] analyzed seven randomized trials, which included at least one group with only one immediate instillation of a chemotherapic agent. Among 1476 patients included in this meta-analysis, with a median follow-up of 3.4 years, 362 of $748(48.4 \%)$ of patients treated with TUR alone had a recurrence, whereas 267 of $728(36.7 \%)$ of those receiving a single instillation of a chemotherapy agent had a recurrence. This difference means a significant decrease in the risk of recurrence of $39 \%$ (odds ratio of $0.61 ; p<0.0001$ ). This positive impact on recurrence is observed for patients with solitary tumors (odds ratio of 0.61 ) as well as for multiple tumors (odds ratio of 0.44 ); although the significant reduction of recurrence in patients with multiple tumors when receiving a single immediate instillation the recurrence rate was very high, $65.2 \%$. This high recurrence means that a single immediate instillation, even though positive, is an insufficient approach for these patients needing more instillations. Moreover, in other randomized trials not included in this meta-analysis, by administrating more than one single instillation, it was demonstrated that an early instillation was also effective in patients with multiple tumors than those not receiving an immediate instillation[29,31].

One controversial issue is the timing of the instillation. As a whole, the instillation was generally administrated immediately or within $6 \mathrm{~h}$ after the TUR. This seems a suitable period to achieve the highest effectiveness. Whether or not the chemotherapy instillation is effective after this period remains unknown. However, Kaasinen et al.[32] analyzed a randomized series of patients receiving an intravesical instillation after $24 \mathrm{~h}$ because of protocol deviation and found that the recurrence rate was almost double that for those who received the instillation within $24 \mathrm{~h}$ after TUR. Although the suitable period seems to be within $6 \mathrm{~h}$, this might be enlarged to $24 \mathrm{~h}$, but no longer.

The role of bacillus Calmette-Guerin (BCG) in the low-risk group is poorly understood as, in general, BCG is not used for these patients. However, in two meta-analyses, BCG was not superior to MMC in lowintermediate risk groups[33,34]. Only when maintenance was applied was BCG superior to MMC[33], however, nonrandomized trials were included in this stratification of the meta-analyses and some methodological problems make this evidence very weak. In another meta-analysis, BCG was only superior to intravesical chemotherapy when this approach was applied after intravesical chemotherapy failed[35]. On the other hand, in all meta-analyses, BCG was significantly more toxic than intravesical chemotherapy regardless of the scheme used. In consequence, BCG seems not to have a role as an initial treatment in the low-risk group, but probably could be effective as a rescue therapy when intravesical therapy fails.

\section{MECHANISM OF ACTION}

Most of the results of trials using a single immediate instillation were analyzed in short-term follow-up. The impact of this approach in long-term follow-up was analyzed by Solsona et al.[13] who compared a single instillation of MMC and TUR alone. With a median follow-up of 94 months, the recurrence rate was dramatically reduced during the first months, reaching the statistical significance at 24 months evaluation ( $p=0.013$ ), and this difference was maintained during the follow-up according to the Kaplan Meier method in which curves run parallel (Fig. 1). Rajala et al.[26], with a median follow-up of 72 months comparing a single instillation of epirubicin, also observed that curves run parallel during the follow-up after an initial separation. Both series confirm that the efficacy of an immediate instillation is concentrated during a short interval from the instillation and, after this period, the natural history was not modified by this approach. The critical period of this approach was also studied by Solsona et al. who reported that this period was concentrated during the first year (Fig. 2), with a recurrence rate of 3.5\% in the immediate instillation arm and $20.3 \%$ in the observation arm $(p<0.05)$. However, after 12 months, the recurrence rate of both approaches was similar, 36.8 and 32.8\%, respectively. According to these 
observations, one can speculate that the working mechanism of an immediate instillation is to eliminate floating tumor cells, preventing the cells' implantation at traumatized bladder mucosa after TUR. In animal models, a potential cell implantation as responsible for early recurrence in the bladder was demonstrated, as well as the inhibition of implantation cells by thio-tepa in cauterized bladder mucosa[36]. Also, a potential chemoresection of residual tumors has been suggested. Masters et al.[37] observed a $44 \%$ marker lesion disappearance after a single instillation of epirubicin. However, that a single dose is able to achieve the complete elimination of residual tumor needs more scientific support.

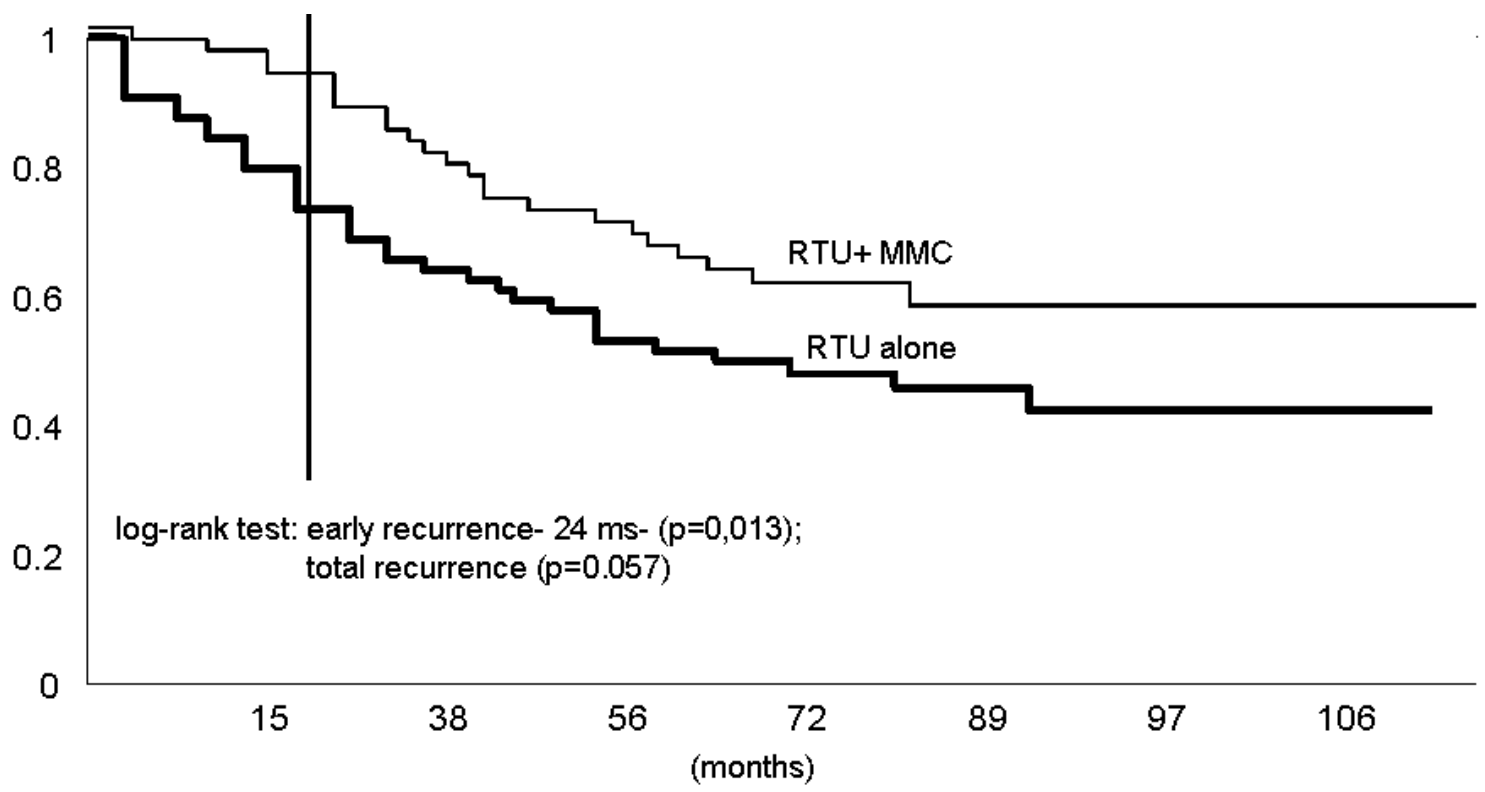

FIGURE 1. Recurrence-free survival comparing a single immediate chemotherapy instillation and observation. Short- and longterm follow-up.

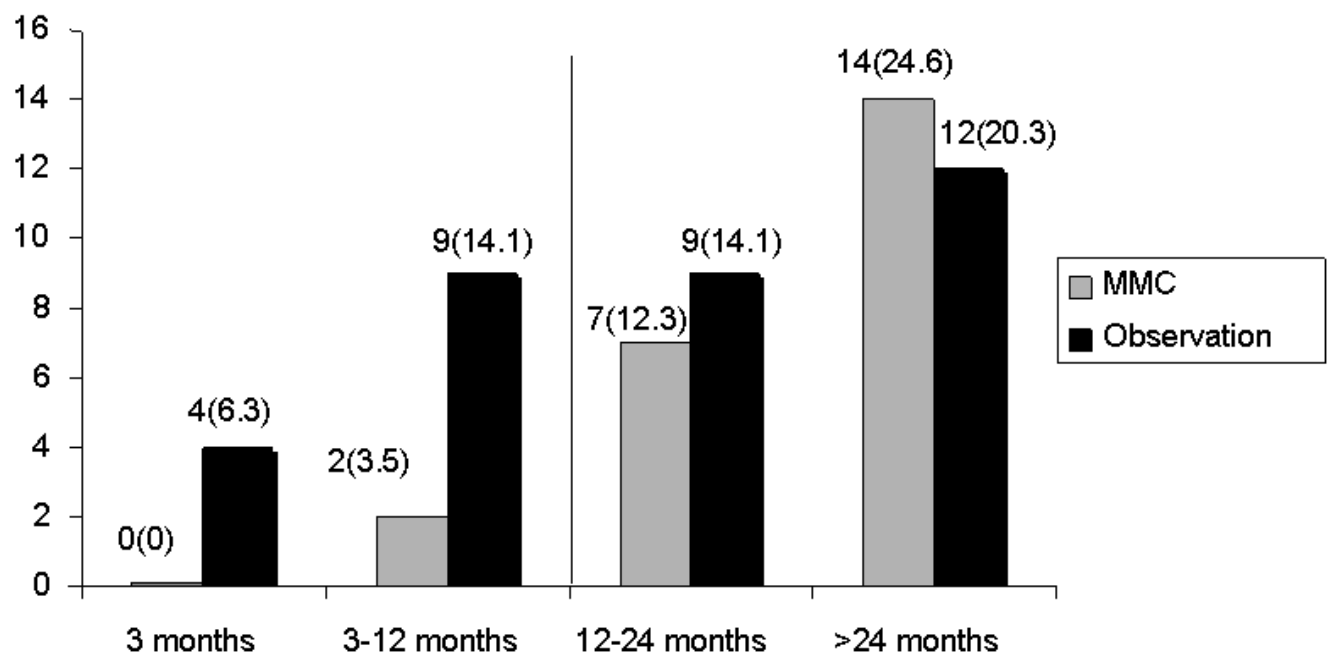

FIGURE 2. Recurrence percentage comparing a single immediate chemotherapy instillation and observation. Time of recurrence. 
Oosterlink et al.[10] calculated that the NNT (number needed to treat) to prevent one recurrence was 8.5, meaning a cost reduction in terms of surgery and hospitalization.

\section{TOXICITY}

The tolerance of an immediate instillation is usually excellent with minimal side effects. In the Solsona et al. series, a 3.5\% slight chemical cystitis and skin reactions were observed in the MMC arm and only $1.5 \%$ in the observation arm[13]. This minimal side effect was also reported in the meta-analysis carried out by Sylvester et al.[30]. However, severe side effects have been published, particularly chemical pericystitis related to drug extravasation due to bladder perforation[38]. Although these severe complications are unusual, some precautions should be adopted when a bladder perforation is suspected during TUR. In these cases, an immediate instillation should not be administrated. In cases of hematuria, the instillation should be delayed until the cessation of the hematuria, due to potential urinary retention and urine extravasation.

\section{FOLLOW-UP}

Regardless of the good prognosis for patients included in the low-risk group, they should be followed according to the high recurrence rate. However, early detection should not be as important as in intermediate- or high-risk groups since the recurrences usually are the same category than the initial pathology and the progression rate is extremely low[11]. During the follow-up, patients with TaG1 tumors who progressed to higher grade ranged from $13.4-16.3 \%[39,40]$, only $3.3 \%$ to $\mathrm{T} 1$, and from $1.1-$ $3.3 \%$ to muscle-invasive bladder tumor. In a series of a clinical low-risk group with a median follow-up of 94 months, only $1.5 \%$ developed progression to invasive tumors[13]. Soloway et al.[41] observed a growth of $1.77 \mathrm{~mm} / \mathrm{month}$ in 32 patients with low-grade tumors only. Among these patients, only three increased to a higher grade or stage, meaning that the delayed TUR does not threaten the prognosis of these patients. According to these data, the follow-up schedule should include the cystoscopy and urinary cytology at 3 months as the great prognostic value of this evaluation[10] and if this is negative, the cystoscopy can be spared for 9 months followiing Oge et al.'s proposal[42]. The duration of the follow-up should be indefinite as the risk of recurrence remains life-long. However, many cystosocpies should be replaced by ultrasounds and cytology according to expert opinion. Regardless, the high sensitivity of urinary markers, whether they can replace cystoscopy, remains to be defined as there is no scientific evidence proving their efficacy in this group within the balance of cost/efficacy[10].

In case of recurrence, the best therapeutic approach remains controversial. Herr[11], based on the accuracy of cystoscopy appearance in patients with recurrent TaG1 and negative cytology, proposed only fulguration in the office. Of 69 patients who underwent office fulguration, 22 required TUR and 3 had muscle-invasive tumors. In a prospective study from the same institution, of 267 consecutive patients with recurrent tumors, 103 underwent only fulguration because they had low-grade appearance, $<5 \mathrm{~mm}$, and negative urinary cytology. There was no greater risk of progression in these patients than in those treated with TUR because they did not fulfill the prior criteria[10]. In summary, office fulguration seems to be an alternative to TUR in selected cases with recurrent TaG1 tumors.

An intravenous urography is not necessary during the follow-up as the recurrence in the upper urinary tract is extremely low in patients at low risk[10].

\section{CONCLUSIONS}

Patients with nonmuscle-invasive bladder tumors at low risk constitute a group with high recurrence and low progression rates. A single immediate instillation of whatever chemotherapy agent should be considered as the best therapy option within the balance of cost/efficacy. This approach is useful for 
single and multiple tumors, but tumors with worse prognostic factors should be treated with more intensive intravesical chemotherapy, as the efficacy of this approach is limited to the first year and has no influence on the posterior natural history. Office fulguration is a suitable therapy in selected patients with recurrent tumors. BCG does not seem an appropriated treatment for these patients, but it might be considered as a rescue therapy when intravesical chemotherapy fails. Follow-up is necessary, but the schedule is less rigorous than for intermediate- or high-risk groups.

\section{REFERENCES}

1. Murphy, W.M., Takezawa, K., and Maruniak, N.A. (2002) Interobserver discrepancy using the 1998 WHO/ISUP classification of urothelial neoplasms: practical choices for patient care. J. Urol. 168, 968-972.

2. $\quad$ Epstein, J.L., Amin, M.B., Reuter, V.R., and Mostofi, F.K. (1998) The World Health Organization/International Societey of Urological Pathology consensus classification of urothelial (transitional cell) neoplasms of the urinary bladder. Bladder Consensus Conference Committee. Am. J. Surg. Pathol. 22, 1435.

3. Eble, J.N., Sauter, G., Epstein J.L., and Sesterhenn, I.A. (2004) Pathology and genetics of tumours of the urinary system and male genital organs. In World Health Organization Classification of Tumours. IARC Press, Lyon, France. pp. 89-123.

4. $\quad$ Sylvester, R., van der Meijden, A., Oosterlinck, W., Witjes, J., Fouffioux, G., Denis, L., Newling, D., and Kurth, K.H. (2006) Predicting recurrence and progression in individual patients with stage T1-T1 bladder cancer using EORTC risk tables: a combined analysis of 2596 patients from seven EORTC trials. Eur. Urol. 49, 466-475.

5. Oosterlinck, W., Lobel, B., Jakse, G., Malmstrom P.U., Stockle, M., Sternberg, C., and European Association of Urology (EAU) Working Group on Oncological Urology (2002) Guidelines on bladder cancer. Eur. Urol. 24, 105112.

6. $\quad$ Kurth, K.H., Denis, L., Boufioux, C., Sylvester, R., Debruynne, F.M., Pavone-Macualuso, M., and Oosterlink, W. (1995) Factors affecting recurrence and progression in superficial bladder tumours. Eur. J. Cancer 31, 1840-1846.

7. Millan, F., Chechile, J., Salvador, J., et al. (2000) Primary superficial bladder cancer risk groups according to progression, mortality and recurrence. J. Urol. 164, 680-684.

8. Holmàng, S., Andius, P., Hedelin, H., et al. (2001) Stage progression in Ta papillary urothelial tumors: relationship to grade, immunohistochemical expression of tumor markers, mitotic frequency and DNA ploidy. J. Urol. 165, 11241128.

9. Haukaas, S., Daehlin, L., Maartmann-Moe, H., et al. (1999) The long-term outcome in patients with superficial transitional cell carcinoma of the bladder: a single-institutional experience. BJU Int. 83, 957-963.

10. Oosterlinck, W., Solsona, E., Akaza, H., Busch, C., Goebell, P.J., Malmström, P.U., Òzen, H., and Sved, P. (2005) Low-grade Ta (noninvasive) urothelial carcinoma of the bladder. Urology 66(Suppl 6A), 78-89.

11. Herr, H.W. (1990) Outpatient flexible cystoscopy and fulguration of recurrent superficial bladder tumors. J. Urol. 144, 1365-1366.

12. Donat, S.M, North, A., Dalbagni, G., et al. (2004) Efficacy of office fulguration for recurrent low grade papillary bladder tumors less than $0.5 \mathrm{cms}$. J. Urol. 171, 636-639.

13. Solsona, E., Iborra, I., Ricos, J., et al. (1999) Effectiveness of a single immediate mitomycin C instillation in patients with low risk superficial bladder cancer: short and long-term followup. J. Urol. 161, 1120-1123.

14. Oosterlinck, W., Kurth, K., Schröder, F., et al. for the EORTC-GU Group (1993) A prospective European Organization for Research and Treatment of Cancer Genitourinary Group randomized trial comparing transurethral resection followed by a single intravesical instillation of epirubicin or water in single stage Ta, T1 papillary carcinoma of the bladder. J. Urol. 149, 749-752.

15. Cina, S.J., Epstein, J.I., Endrezzi, J.M., et al. (2001) Correlation of cystoscopic impression with histologic diagnosis of biopsy specimens of the bladder. Hum. Pathol. 32, 360-367.

16. Herranz-Amo, F., Diaz-Cordero, J.M., Verdú-Tartajo, F., et al. (1999) Need for intravenous urography in patients with primary transitional carcinoma of the bladder? Eur. Urol. 36, 221-224.

17. Palou, J., Fariña, L.A.,Villavicencio, H., et al. (1992) Upper tract urothelial tumor after transurethral resection for bladder tumor. Eur. Urol. 21, 110-114.

18. Brausi, M., Collette, L., Kurth, K., van der Meijden, A., Oosterlinck, W., Witjes, J.A., Newling, D., Bouffioux, D., Sylvester, R.J., and EORTC Genito-Urinary Tract Cancer Collaborative Group (2002) Variability in the recurrence rate at first follow-up cystoscopy after TUR in stage Ta T1 transitional cell carcinoma of the bladder: a combined analysis of seven EORTC studies. Eur. Urol. 41, 523-531.

19. Miladi, M., Peyromaure, M., Zerbid, M., Saighi, D., and Debre, B. (2003) The value of a second transurethral resection in evaluating patients with bladder tumors. Eur. Urol. 43, 241-245.

20. Abrams, P., Choa, R., Gaches, C., et al. (1981) A controlled trial of single dose intravesical adriamycin in superficial bladder tumors. Br. J. Urol. 53, 585-587.

21. Burnand, K., Boyd, P., Mayo, M., et al. (1976) Single dose intravesical thiotepa as an adjuvant to cystodiathermy in the treatment of transitional cell bladder carcinoma. Br. J. Urol. 48, 55-59. 
22. Garrett, J., Lewis, R., Meehan, W., et al. (1978) Intravesical thiotepa in the immediate post-operative period in patients with recurrent transitional cell carcinoma of the bladder. J. Urol. 120, 410-411.

23. Kurth, K., Maksimovic, P., Hop, W., et al. (1983) Single dose intravesical epodyl after tur of Ta TCC bladder carcinoma. World. J. Urol. 1, 89-93.

24. Medical Research Council Working Party on Urological Cancer, Subgroup on Superficial Bladder Cancer (1994) The effect of intravesical thiotepa on tumor recurrence after endoscopic treatment of newly diagnosed superficial bladder cancer: a further report with long-term follow up of a Medical Research Council randomized trial. Br. J. Urol. 73, 632-638.

25. Ali-el-Dein, B., Nabeeh, A., el-Baz, M., et al. (1997) Single dose versus multiple instillations of epirubicin as prophylaxis for recurrence after transurethral resection of pTa and pT1 transitional cell bladder tumors; a prospective randomized controlled study. Br. J. Urol. 79, 731-735.

26. Rajala, P., Kaasinen, E., Raitanem, M., et al. for the Finnbladder Group (2002) Perioperative single dose instillation of epirubicin or interferon-alpha after transurethral resection for the prophylaxis of primary superficial bladder cancer recurrence: a prospective randomized multicenter study--FinnBladder III long-term results. J. Urol. 168, 981-985.

27. Tolley, D.A., Parmar, M.K., Grigor, K.M., et al. (1996) The effect of intravesical mitomycin C on recurrence of newly diagnosed superficial bladder cancer: a further report with 7 years of follow up. J. Urol. 155, 1233-1238.

28. Okamura, K., Ono, Y., Kinukawa, T., et al. for the Nagoya University Urological Oncology Group (2002) Randomized study of single early instillation of (2"R)-4'-O-tetrahydropyranyldoxorubicin for a single superficial bladder carcinoma. Cancer 94, 2363-2368.

29. Zincke, H., Utz, D., Taylor, W., et al. (1983) Influence of thiotepa and doxorubicin instillation at time of transurethral surgical treatment of bladder cancer on tumor recurrence: a prospective, randomized, double-blind, controlled trial. $J$. Urol. 129, 505-509.

30. Sylvester, R., Oosterlinck, W., and van der Meijden, A. (2004) A single immediate postoperative instillation of chemotherapy decreases the risk of recurrence in patients with stage Ta T1 bladder cancer: a meta-analysis of published results of randomized clinical trials. J. Urol. 171, 2181-2185.

31. Iborra, I., Ricos, J., Monros, J., et al. (1992) Results of a randomized, double-blind prospective study of intravesical chemoprophylaxis with 2 drugs, adriamycin and mitomycin, and 2 ways of initiating the instillations, early and late: effect on recurrence and progression (in Spanish). Arch. Esp. Urol. 45, 1001-1010.

32. Kaasinen, E., Rintala, E., Hellstrom, P., et al. for the Finnbladder Group (2002) Factors explaining recurrence in patients undergoing chemoimmunotherapy regimens for frequently recurring superficial bladder carcinoma. Eur. Urol. 42, 167-174.

33. Bölhe, A., Jocham, D., and Bock, P.R. (2003) Intravesical bacillus Calmette-Guérin versus mitomycin C for superficial bladder cancer: a formal meta-analysis of comparative studies on recurrence and toxicity. J. Urol. 169, 9095.

34. Shelley, M.D., Court, J.B., Kynaston, H., et al. (2003) Intravesical bacillus Calmette-Guérin in Ta and T1 bladder cancer. Cochrane Database Syst. Rev. (3), CD03231.

35. Huncharek, M. and Kupelnick, B. (2003) Impact of intravesical chemotherapy versus BCG immunotherapy on recurrence of superficial transitional cell carcinoma of the bladder, metaanalysis reevaluation. Am. J. Clin. Oncol. 26, 402-407.

36. Pans, J.S., Slocum, H.K., Rustum, Y.M., et al. (1989) Inhibition of implantation of murine bladder tumor by thiotepa in cauterized bladder. J. Urol. 142, 1589-1593.

37. Masters, J., Popert, M., Thompson, P., et al. (1999) Intravesical chemotherapy with epirubicin: a dose response study. J. Urol. 161, 1490-1493.

38. Doherty, A., Trendell-Smith, N., Stirling, R., et al. (1999) Perivesical fat necrosis after adjuvant intravesical chemotherapy. BJU Int. 83, 420-423.

39. Borham, A., Reeder, J.E., O`Connell, M.J., et al. (2003) Grade progression and regression in recurrent urothelial cancer. J. Urol. 169, 2106-2109.

40. Leblanc, B., Duclos, A.J., Bénard, F., Côté, J., et al. (1999) Long-term follow-up of initial Ta grade 1 transitional cell carcinoma of the bladder. J. Urol. 162, 1946-1950.

41. Soloway, M.S., Bruck, D.S., and Kim, S.S. (2003) Expectant management of small recurrent, non-invasive papillary bladder tumors. J. Urol. 170, 438-441.

42. Oge, O., Erdem, E., Atsu, N., et al. (2000) Proposal for changes in cystoscopic follow-up of patients with low-grade pTa bladder tumors. Eur. Urol. 37, 271-274.

\section{This article should be cited as follows:}

Solsona, E. (2006) Best approach for low-risk superficial bladder cancer. TSW Urology 1(S2), 36-43. DOI 10.1100/ tswurol.2006.237. 


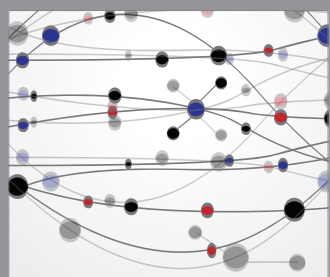

The Scientific World Journal
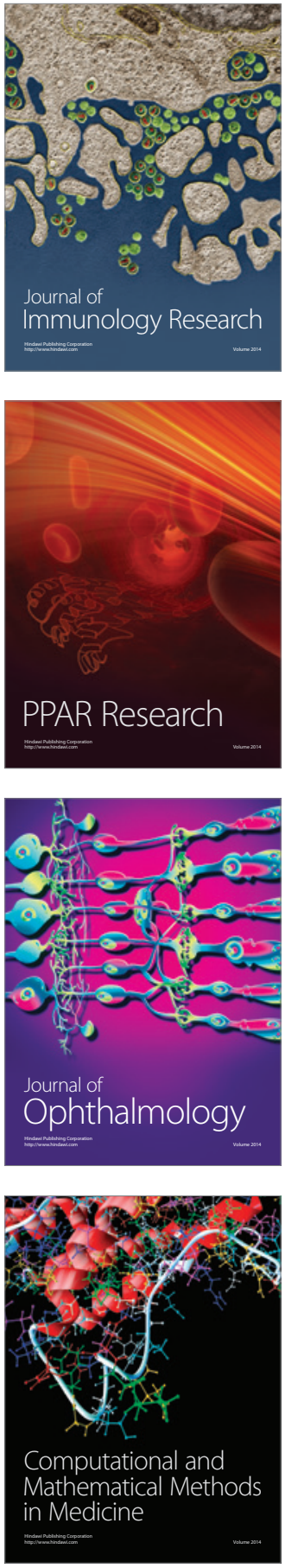

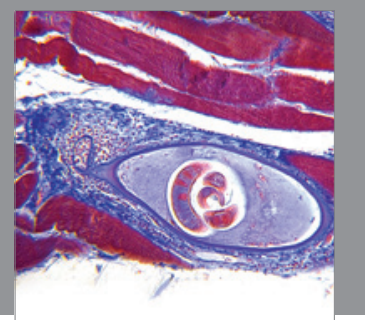

Gastroenterology

Research and Practice
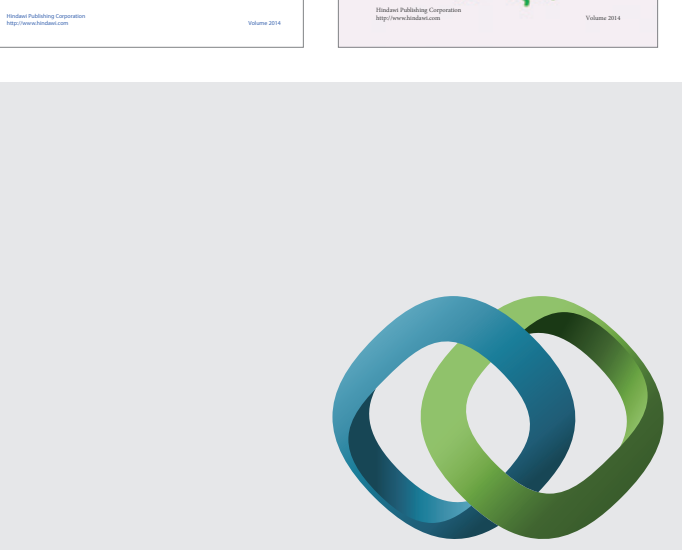

\section{Hindawi}

Submit your manuscripts at

http://www.hindawi.com
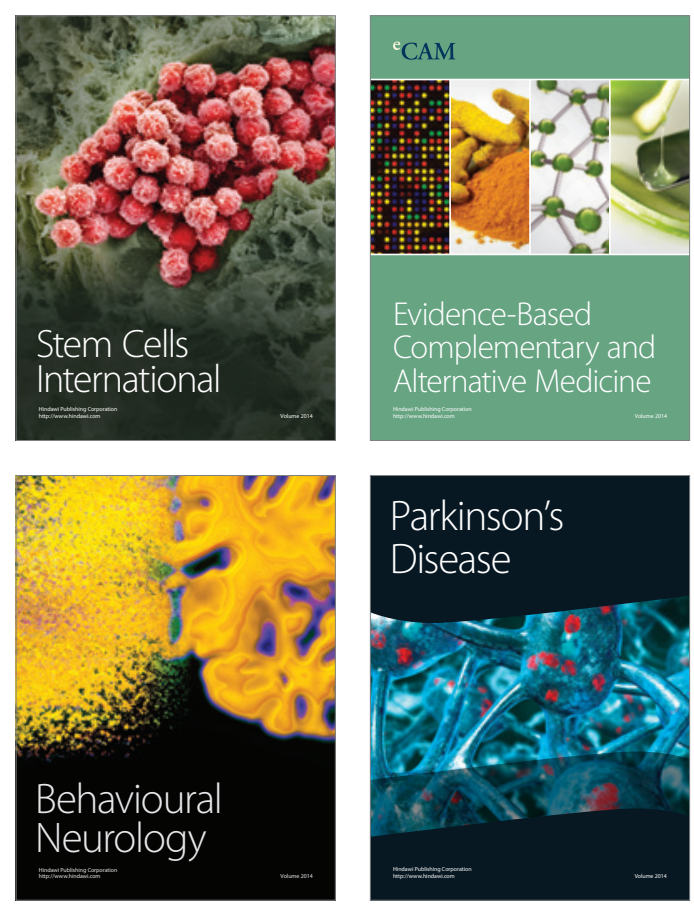

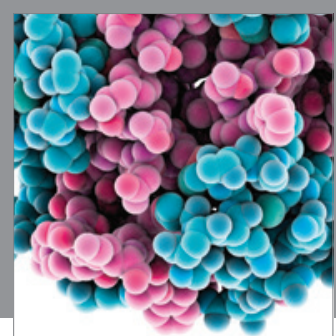

Journal of
Diabetes Research

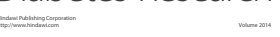

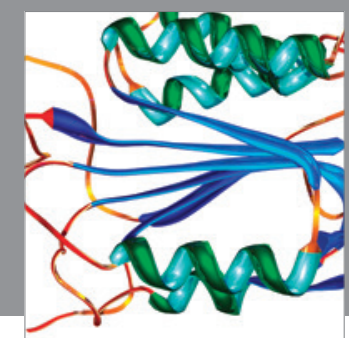

Disease Markers
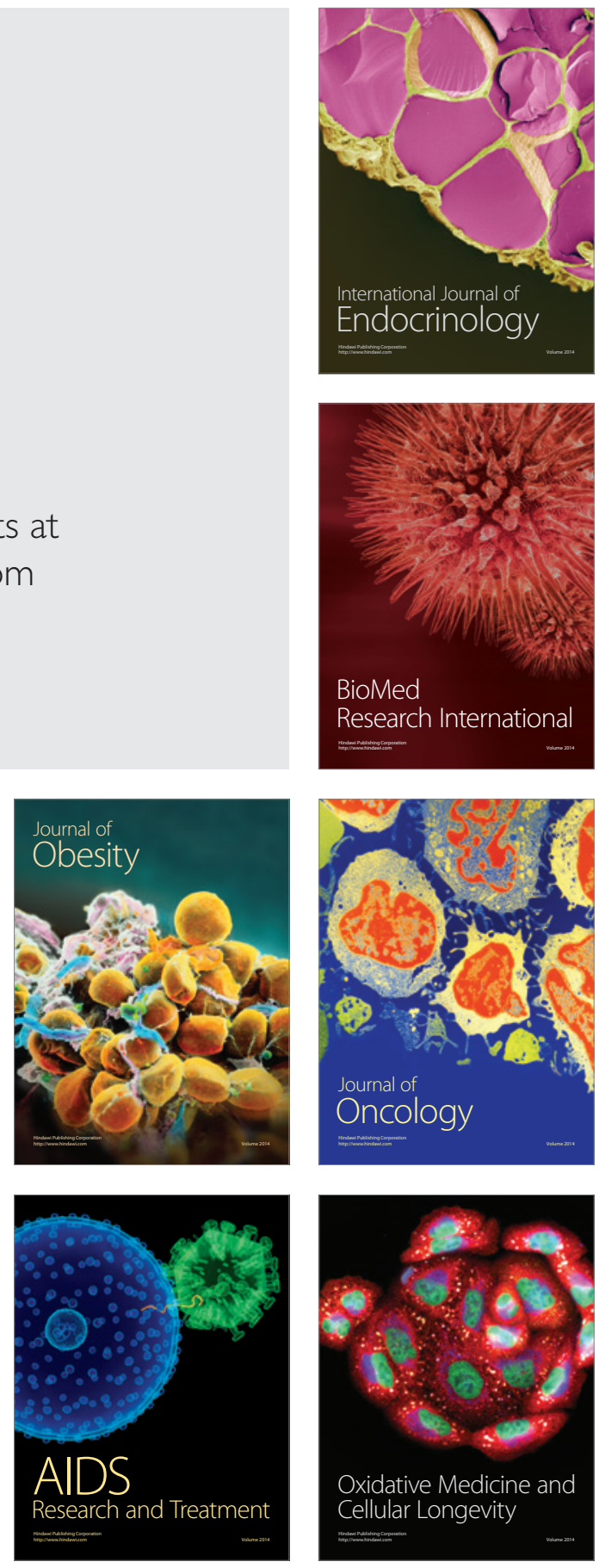